\title{
Enhancing REDD+ Outcomes through Improved Governance of Community Forest User Groups
}

\author{
Bishnu Hari Poudyal*, Govinda Paudel ** and Harisbaran Luintel *** \\ *Grassroots Capacity Building for REDD+ in Asia, RECOFTC - Nepal \\ $* *$ ForestAction Nepal \\ *** The School of Environment, Portland State University, USA \\ Corresponding author: bishnuharipaudel@yahoo.com
}

\begin{abstract}
Since forests are both source and sink of carbon, scholars have suggested reducing emissions from deforestation and forest degradation, including conservation and sustainable management of forest and enhancement of forest carbon stock (REDD+) to be part of climate negotiation. Studies have shown that forests can play a role in reducing emissions in a cheaper, quicker and effective way, while generating important co-benefits, including biodiversity conservation and watershed management. However, governance that shapes relations between different stakeholders at grassroots level has been shown to be a crucial issue in managing local forests in a way that sequester more carbon from, and emit less of it to, the atmosphere. The authors of this paper argue that the lessons gained at community forest user group (CFUG) level regarding forest governance could be useful in designing a REDD+ governance structure at grassroots level. For this, both positive lessons and challenges faced so far could be documented, analyzed, synthesized and shared at broader level. REDD+, being an external intervention to local communities, can bring a range of challenges that influence the governance dynamics. However, if the programme is managed carefully, CFUGs are capacitated adequately and governed collaboratively, REDD+ may bring synergistic outcomes with existing community forestry at grassroots level, particularly by bringing both environmental and livelihood benefits.
\end{abstract}

Key words: Internal good governance, REDD+, CF, sustainable forest management

\section{INTRODUCTION}

Community forestry (CF) in Nepal has become a successful example of devolved community rights in managing common property resources. Legal provisions in the Forest Act (1993) such as the rights to organize, protect, manage and utilize forest resources have increased community ownership over local forests and empowered the community in taking decisions regarding forest management. During the last three decades and a half, CF has significantly contributed to forest management, livelihood support, community development, social change and strengthening democratic practices at local level (Pokharel et al. 2007; Luintel et al. 2009). However, challenges and issues related to forest outcomes such as sustainable management of forest, communities' livelihood, social inclusion and governance of community forest user groups
(CFUGs) have emerged gradually in recent years. In this context, community rights and autonomy over forests have been recognized as crucial factors for improving overall forest outcomes (Arnold and Stewart 1991; Charnley and Poe 2007). Realizing community rights and autonomy and achieving synergy between forest outcomes primarily depend on fair and equitable internal good governance of CFUGs (Poudyal et al.2010). Now, the Government of Nepal (GoN), donor communities and civil society organizations (CSO) have been putting efforts in improving CFUGs' internal governance as a key area of intervention. The CF Guidelines (revised in 2008) has also highlighted the importance of promoting internal governance of CFUGs for better forest outcomes (CFD 2009). 
The recent climate change debate under the United Nations Framework Convention on Climate Change (UNFCCC) has proposed $\mathrm{REDD}+{ }^{1}$ as a strategy for mitigating climate change, which according to Stern (2006) is considered a quick, effective and cheap mechanism. When carefully designed, REDD+ can provide additional benefits for community livelihoods (Angelsen and McNeill 2012) and biodiversity conservation (Venter et al. 2009). Scholars have argued that policymakers can improve the likelihood of success of REDD+ with the use of success factors ${ }^{2}$ of $\mathrm{CF}$ management (Agrawal and Angelsen 2009) and incorporation of biodiversity considerations and livelihood goals (Visseren-Hamakers et al. 2012).

REDD + demands a high priority on effective forest governance and institutional capabilities so that sustainable management of forests and enhanced carbon stock can be achieved. Due to its associated factors with drivers of deforestation and concerns of livelihoods, REDD+ has been a socioeconomic and political agenda beyond carbon. Therefore, in addition to carbon benefits, it should address the social issues of forest management. This can be achieved only when transparency and accountability; free, prior and informed consent; equitable benefit sharing and social inclusion are assured (Springate-Baginski and Wollenberg 2010). For CFUGs to become viable and eligible local institutions for REDD+ implementation, special attention to CFUG governance is required. Similarly, CFUGs' governance is equally important to ensure that the REDD+ outcomes are institutionalized and distributed equitably.

This article attempts to highlight the key aspects of CFUGs' governance and its role in enhancing the REDD+ outcomes. Although the prospects of REDD+ implementation through CF have been studied, consensus among researchers on the outcomes is still debated. In this article we present existing governance practices of CFUGs and discuss their relevance to REDD+. The first section introduces the importance of CFUG's governance in REDD+, while the second section highlights the methods of this study. Existing practices of CFUGs' governance are elaborated explicitly in the third section by taking two cases from the field. The fourth section discusses the significance of CFUGs' governance practices in promoting climate change outcomes through the implementation of REDD+. The final section concludes the paper.

\section{METHODOLOGY}

The article is an outcome of a CFUG governance study by Poudyal et al. (2010), which employed the CFUG governance assessment framework proposed by Luintel et al. (2007). The framework has introduced some important nonconventional parameters into the scene of CFUG governance. These include (i) participation and voice, (ii) heterogeneity and inclusiveness, (iii) access to forestlands, territories and related practices, (iv) accountability and transparency, (v) power relations, dispute resolution and equity, (vi) agencies of change and respect for local knowledge, (vii) implementation, selfmonitoring, adaptive capacity and collaboration, (viii) planning and decisionmaking practices, (ix) constitution, compliance and enforcement of rules at local level, ( $\mathrm{x}$ ) mechanisms to monitor the macro environment, and (xi) effectiveness and efficiency.

Relevant literature was reviewed in determining whether the given parameters were sufficient

${ }^{1}$ Reducing Emissions from Deforestation and Forest Degradation, including Conservation and Sustainable Management of Forests and Enhancement of Forest Carbon Stocks

${ }^{2}$ These factors include sufficient size, clear boundaries of forests, predictability of benefit flows, local autonomy in rule making (Agrawal and Angelsen, 2009). 
to assess CFUG governance. Expert consultation $^{3}$ aided in assessing the emerging knowledge of governance in the face of environmental value of forest.

Considering diverse community contexts in terms of socio-cultural, ecological and geographical variations, Patle CFUG of Lalitpur district and Sundari CFUG of Nawalparasi district were selected for the field study. The required data were collected through meetings with the members of the executive committees (EC), transact walks, focus group discussions (FGDs), key informant interviews (KIIs), expert consultations and observations of CFUG activities. Moreover, secondary information was collected from the records of the district forest office (DFO), village development committees (VDC) and the Federation of Community Forestry Users, Nepal (FECOFUN).

\section{KEY FEATURES OF CFUGS AND THEIR GOVERNANCE PRACTICES}

\section{Historical and Biophysical Features of the Selected CFUGs}

Patle CFUG: Patle CFUG is located in Lamatar VDC of Lalitpur district in Kathmandu valley. A total of 158 households (HHs) have been managing 119 hectares (ha) of forest. Ranging from 1,400 to 1,800 metres in altitude, this subtropical forest represents the middle hill forest and is primarily dominated by broadleaved tree species that are not commercially valuable but are important for local livelihoods.

Local forest management initiatives started in 1991 when local people formed a forest users committee to protect and manage the forest. Initially, they had the dual objective of promoting forest productivity and supplying the basic forest product needs of the community. A forest guard was appointed, and every households collected money to pay the salary of the forest guard. In $1997^{4}$, the DFO officially handed over the forest to the community. The community was able to control overgrazing and rampant forest fires. As a result, forest productivity is restored; forest product supplies are increased and biodiversity is enhanced. The community fund also increased significantly, the sale of forest products being the major source of the fund. Other sources included the revenue generated through drinking water supplies, imposition of fines and penalties, and grants from government and non-governmental organizations (NGOs) for forest management activities. These days, the members of this CFUG are increasingly becoming aware of payments for environmental services (PES) as well. CFUG developed its own operational plan (OP) - a detailed plan of community forest management activities - and group constitution (plan of internal governance). Recently, it has amended its constitution and OP for ten years. These plans stipulate that the CFUG will be self-reliant in forest products and become a prosperous community.

Sundari CFUG: Sundari CFUG is located in Amarapuri VDC in Nawalparasi district. The community comprises 1,533 households and has been managing 385 ha of forest. Located in the southern lowlands, Terai, from $650-700 \mathrm{~m}$ in altitude, it has a productive forest, rich in valuable timber stock (such as Shorea robusta) and, therefore, earns higher income each year.

During 1997, when CF was gaining momentum in its expansion in the middle hills of Nepal, some young local people started a dialogue with the local forestry officials to devise a pragmatic approach to local forest management in the village. This led to forming a forest protection committee chaired by a young leader. The DFO

\footnotetext{
${ }^{3}$ Six experts in the areas of environmental governance, local governance, forest management and livelihoods were consulted.

${ }^{4}$ The CFUG was registered with the DFO on 3 June 1993, and was approved on 30 January 1997
} 
provided support to the community to prepare necessary legal documents, including the group's constitution and OP. The DFO registered the CFUG, approved its OP and formally handed over the forests to the community in 1998. As stipulated in the forestry policies ${ }^{5}$, Sundari CFUG has amended its OP twice since the time of its establishment: first in 2002 and second in 2008.

Active participation of the local people, coupled with strong legal backing, significantly contributed to reviving the forest conditions. Under the initiative of the local community, haphazard grazing, forest fire, illegal logging, encroachment and shifting cultivation were controlled, thereby enhancing forest productivity, biodiversity richness as well as watershed protection. In addition, the community fund significantly increased from the sale of forest products, membership fees, fines and penalties, and grants from both government agencies and NGOs. These days the CFUG generates about 3.5 million Nepalese Rupees (approx US\$ 42,000) annually from the sale of timber within the CFUG. The price of the timber is highly subsidized by the CFUGs for the community members (about $25 \%$ of the market price). The CFUG has been utilizing the fund for construction of roads, drinking water, schools, pro-poor income generation, forest management and support to disabled persons. Sundari CFUG has its own office premises with a facility for residential training, a forest nursery and a non-timber forest product (NTFP) demonstration plot.

\section{Existing Practices of Governance in the Selected CFUGs}

The study analyzed the governance practices of these two CFUGs using the framework stated earlier. The framework goes beyond the classical four-pillar approach of governanceparticipation, transparency, accountability and rule of law-to understand the complex relationships within communities and between the communities and other actors. Here, we briefly describe the CFUGs' engagement in terms of identified governance parameters.

Participation and voice: Both CFUGs are promoting participation of users at grassroots level through multiple arrangements such as general assembly (GA), tole ${ }^{6}$ or $\operatorname{ward}^{7}$ assemblies, executive committee (EC) meetings, etc. These decision-making fora provide opportunities for CFUG members to voice their concerns. This has encouraged people, particularly dalits ${ }^{8}$, women, poor and other marginalized groups to participate in CFUG activities such as electing EC members and taking decisions about forest management and benefit sharing.

CFUGs have rules to ensure participation through allocating special quota for dalits, women and marginalized people in the EC and other institutional structures. These provisions are instrumental in increasing participation. However, there are constraints on participation of these groups. Dalits feel more comfortable to express their views at tole meetings than in the GA. Sometimes, they find their concerns and voices being overlooked in the GA. Similarly,

\footnotetext{
${ }^{5}$ Primarily, forest policies include The Forest Act 1993, Forest Regulation 1995, and CF Guidelines

${ }^{6} \mathrm{~A}$ small settlement located in a small geographical area where people generally share common interest, problems and aspirations regarding forest management.

${ }^{7}$ The lowest administrative and political unit of local government.

${ }^{8}$ The so-called 'untouchable' groups are highly marginalized from mainstream development and bottom-layered groups in Nepali hierarchical society.
} 
dalit women have other pressing concerns. They have experienced discouragement and humiliation at the hands of the so-called higher castes when they participate in the GA. Since dalits and poor are mostly daily wage labourers, most of them are too tired by their routine work and cannot actively participate in every discussion.

Heterogeneity and inclusiveness: Due to the influx of immigrants from various parts of the country, the central Terai of Nepal (e.g. Sundari CFUG) is more heterogeneous than the middle hills (e.g. Patle CFUG). Heterogeneity comes from ethnicity, class, caste, age, education, occupation, gender, geographical location and political ideology. CFUGs have introduced a wide range of institutional mechanisms for addressing the needs and interests of heterogeneity. Provisions of special facilities to dalits and the poor; reserved quotas for women, dalits and ethnic communities in representation/leadership positions; and special care to disadvantaged communities while implementing programmes are some of the innovations to address the diverse needs and interest of the community. Institutional arrangements such as the provision of different sub-committees (advisory, monitoring and evaluation, internal audit and poverty reduction sub-committees) have provided space for the poor, marginalized, dalits and women in leadership positions. However, the prevailing caste-based hierarchy in the community has maintained discrimination in different manifestations (such as untouchability) and precluded dalits from enjoying community benefits.

Access to forest, lands, territories and related practices: CFUGs exercise their 'bundle of rights' in forestry based on legal provisions stipulated in their constitutions and OPs. The right to become a CFUG member is based on the inherited land titles within the boundary of the community. However, immigrants are eligible to become CFUG members when they permanently live in the community and pay the 'differentiated entry fee'. CFUGs have developed criteria to determine the entry fee, for example, free membership for the poor and landless. The right to access forests is important as the presence of legal and/or customary rights over forest resources creates incentives and/or disincentives to the CFUG members to invest in forest management activities. The Forest Act 1993 has provisions that define ownership over forests. For example, government holds the land ownership of the community forest, whereas CFUGs have 'use rights' to the forest products and services.

Accountability and transparency: Both CFUG and EC members are aware that accountability and transparency are important for better governance. Both CFUGs responded that their actions were in line with government policies, as well as with their own constitutions and OPs. The ECs are made accountable to the CFUGs through different institutional mechanisms and processes such as GAs and tole/ ward assemblies. This has helped strengthen trust amongst users. Formation of account subcommittee for internal audit is one example to maintain financial integrity. The external audit through government registered firms has also been made mandatory, as per the government rule. The audit reports, as well as other decisions made by the EC, have to be presented and approved in the GA each year. However, there is still a need to reflect on the effectiveness, efficiency and outcomes of such institutional practices.

Power relations, dispute resolution and equity: The two CFUGs in this study have witnessed direct or indirect effects of power dynamics on CFUG governance and resource

${ }^{9}$ The CFUGs' entry fees are 'differentiated' on the basis of well being (rich or poor or landless), distance (living close to or away from forest), and use of forest product types (all or selected products). 
management. Caste, class, education, political affiliation and social leadership are a few factors that weaken or strengthen governance practice. This ultimately determines the strength of an individual's position in the decision-making process. The EC and sub-committees exercise their formal power in carrying out CFUGs' activities, whereas political parties influence CFUGs indirectly in the elections of the EC. From the interaction with the members of Sundari CFUG, it was revealed that the CFUG did not have any serious disputes among members in forest governance. However, in Patle CFUG, most of the members still believed CF had 'EC-controlled' governance, which sometimes created conflicts within the group.

Agencies of change and respect for local knowledge, value, skills and management systems: Interactions in CFUGs revealed that individual leadership qualities and characteristics had a major influence in bringing changes at CFUG level. Community members believed that the role of external agencies has been crucial to introduce and institutionalize innovative practices and reorient local leadership to facilitate social and biophysical changes. CFUGs appreciated the role of trained local change agents for making social change and innovations in forest management. It has also been revealed from most of the FGDs that the respect of local knowledge, values, skills and management efforts is instrumental to introduce innovative practices. However, some of the traditional social values are discriminatory and, therefore, need change in people's mindset.

Planning and decision-making: The study shows that the CFUGs had lots of innovations to ensure inclusion of oppressed communities like dalits, women and the poor. The concept of tole- or hamlet-level assemblies is one such innovation where users feel free to share their interests than they do in the GA. Moreover, the agenda adopted in such assemblies become the tole's collective interest, capable of influencing decision making at CFUG level. The tole's collective voice is stronger than an individual's interests or viewpoints. Similarly, the formation of other sub-committees, including an advisory committee, also contributes to the planning process where the poor, dalits, women and other marginalized communities push their agenda and concerns. However, the functions and role of sub-committees sometimes become rudimentary and ritual. Our study found that the CFUG planning and decision process have been influenced by multiple actors operating at national, district and local levels such as forest bureaucracy, CSOs, federations and networks, political parties, donors and their projects.

Implementation, self-monitoring, adaptive capacity and collaboration: The CFUGs have contributed to a wide range of community benefits, such as capacity building, empowerment, livelihoods improvement, income generation and democratization of the CFUG practices. CFUGs have implemented most of the decisions made collectively by the EC and GA. These decisions were backed up by different monitoring mechanisms such as participatory self-monitoring (by CFUG itself) and monitoring by the government (i.e. through DFO). Self-monitoring has enhanced the quality of the CFUGs' activities and helped to build trust among different [sub] committees that have engaged many people and, hence, has been effective in checking malpractice and promoting good practices. Self-reflection, interaction and review within the CFUGs have increased their adaptive capacity. The CFUGs have been collaborating with other local-level institutions successfully, particularly in managing forests and carrying out community development. However, sub-committees are not adequately inclusive and, therefore, concerns about the quality of outcomes of such activities has been raised at times.

Constitution, compliance and enforcement of rules at local level: Despite some challenges, CFUG members are complying with the groups' constitutions and OPs. Compliance of the 
provisions made in these documents becomes impractical, complex and challenging when they are externally influenced. For example, people (and documents) in Patle CFUG have indicated about externally-induced provisions in these documents, which are related to climate change, payment for environmental services and pollution. As these are less prioritized issues for the CFUG than the inclusion and livelihoods issues of dalits, women and the poor, the provisions made in the constitution and OP have received less attention. Socio-economic factors also have implications for the compliance of CFUGs' rules. For example, while implementing rules, including penalty provisions, EC seemed less sympathetic towards the poor and marginalized ones living close to the forest (e.g. in Sundari) and remain silent while users of high social status don't comply with the rules (in Patle).

Mechanism and capacity to monitor the macro-environment: Though EC members have a little knowledge about the global and national forestry issues, trends in policy development and discourses on forestry, the CFUG members, in general, lacked enthusiasm on these updates. However, they have mentioned a few provisions related to biodiversity, payment for environmental services or carbon trading in their OP, which have been adopted from elsewhere. Patle CFUG is very close to the national capital, Kathmandu, and has access to many information sources, including different agencies that have executed projects in the area. However, it has neither enthusiasm nor any mechanism in place to foster institutional learning, particularly from the greater understanding of the macroenvironment, i.e the broader context of forestry development. They have learnt a few global concepts, not from internalized institutional learning mechanism, but from media and training/workshops organized by external agencies.
Effectiveness and efficiency: Most of the users appreciate the performance of the EC for their efforts in making CFUG effective and efficient. The EC's efforts have been successful in increasing the CFUG fund and are found to be effective in restoring the greenery and supplying daily forestry needs. However, improvements are necessary to enhance effectiveness and efficiency. They are still not able to deliver sufficient and needed services on time. Although the CFUG fund has significantly increased, propoor income-generating activities receive little priority. Despite the sensitivity to the issues of poverty, livelihoods and inclusion, the capacity and competence of EC to respond to the needs of poor and marginalized groups is not sufficient.

\section{SIGNIFICANCE AND IMPLICATIONS OF CFUGs' GOVERNANCE IN REDD+ OUTCOMES}

Drawing from the case studies and literature, this section articulates the relevance of CF lessons to the REDD+ scheme.

\section{Participatory, Inclusive and Transparent Decision Making}

The central idea of participation is to promote inclusion (Agarwal 2001). Participation is one of the fundamental principles for recognition of the rights of forest-dependent communities in the REDD+ schemes (Sikor et al. 2010). As highlighted by Ribot et al. (2008), cases discussed above demonstrate that the participation of CFUGs in the REDD+ scheme requires policies and procedures. CFUGs' practice of forming different sub-committees strategically provides space not only to socially prestigious people but also to the poor and marginalized. Similarly, CF has been successful in benefiting the poor and increasing the participation of the poor, women and Dalits (Pokharel and Niraula 2004). Learning from the CF practices such as 
institutionalization of discussion and sharing spaces, equitable benefit-sharing practices and addressing the issues of social heterogeneity could be instrumental for better REDD+ governance. This forms the part of synergy between CF and REDD+, thereby leading to better outcomes and fair sharing of carbon and non-carbon benefits. Moreover, by drawing lessons from CF, the REDD+ scheme can embrace the very essence of community participation in its design itself. Placing an inclusive process for formulating a strategy for REDD+ could be an effective intervention to promote participation and transparency in the process. Similarly, decentralized forest management helps to enhance participation of local people in decision-making (Sikor et al. 2010).

However, the discriminatory socio-cultural norms, practice of decision-making based on the majority and scanty or unorganized voices of marginalized in the CFUGs might restrict participation of certain groups of people in the CF as well as REDD+ initiative. Similarly, participation could be broken down in its essence at any stage of the process. For example, Pokharel and Nurse (2004) have summarized the case of exclusion in the CF participation process as follows:

The poor suffer the most in CFUGs as they cannot afford to participate; if they do, they hardly speak; if they speak, they are rarely heard and if heard, hardly get decisions made in their favor; if decision made, very few decisions are implemented and if implemented, only a few get benefits.

So far, it has been noticed that CFUGs' efforts towards effective and meaningful participation of all through experience-based innovations are still inadequate to actively engage the poor and marginalized in the CF processes itself. Therefore, exclusive efforts are important to promote the quality of participation of the community forest stewards in the REDD+ processes. Perhaps, the application of free, prior and informed consent might help the REDD+ scheme to ensure effective and meaningful participation of CFUGs. Also, forming an alliance and network of CFUGs might be needed to meet the required scale for the REDD+ scheme to operate. This might cause greater complexities in managing alliance, network and/or CFUGs, as larger and ethnically diverse groups are more complex to manage (Springate-Baginski et al. 2003). In such case, attention to capacity building and empowerment of the poor and marginalized might be useful. Also, the role and influence of different sets of actors may need to be analyzed and managed as required.

\section{Access, Equity and Power Relations}

Equitable distribution of REDD+ benefits between heterogeneous forest stewards is another principle that recognizes the rights of CFUGs in forest resources under the REDD+ scheme (Sikor et al. 2010). The presence or absence of legal and/or customary rights to forest, carbon and land affects the flow of REDD+ incentives to the forest managing communities (Robledo et al. 2008). Safeguarding rights over, and access to, forest resources and REDD + benefits creates incentives and/or disincentives for the CFUGs to invest in forest management activities and, therefore, affects the REDD+ outcomes. While the right to forest carbon is yet to be defined legally, the right to forest resources and land rests with the CFUGs and the state respectively. In this situation, there is high likelihood of conflicts between the state and communities in getting REDD+ benefits from the community forests. Only a few CFUGs and a few of their members were aware of the forest land tenure systems and their implications for REDD+ benefit sharing. However, awareness programmes might be instrumental in making CFUGs aware of the land tenure system and their implications for forest resource rights and REDD+ incentives. Despite the limited knowledge of forest tenure and implications of REDD+ for forest rights, 
commitment of CFUGs to secure CF rights and to make REDD+ a success seems to be encouraging.

As the value of forests grows locally (for livelihoods and community development) and globally (for environmental services), different types of stakeholders with often diverse and conflicting interests have emerged in the forestry sector. Stakeholders' access to resources, equity in benefits (cost) and opportunity (challenges/ risk) sharing and dynamics of power relations, which are the key factors that determine governance outcomes, have been more complex and ambiguous. This may lead to frequent changes in the interactions of these stakeholders' resulting influence on governance mechanism, benefit sharing, gender equity, resource management, conflict resolution and the CF processes that have direct bearing on REDD+ outcomes (Pokharel 2006). For example, the government forest bureaucracy is still exercising its power to control forest product harvesting, distribution and sale in $\mathrm{CF}$, though its role has already been changed from policing to facilitating (ibid). Despite having autonomy legally, CFUGs are still not sufficiently empowered to determine the price of forest products independently. The local forestry bureaucrats and/or the local political leaders either formally and/or informally affect CFUGs' resource governance and management activities. In this context, there is high likelihood that the government may want to subtly strengthen its role in governing and managing the already devolved forests in the name of REDD+ (Khatri 2012).

\section{Compliance, Monitoring and Adaptive Capacity}

It has been observed that CF has contributed remarkably to the improvement in forest management, social mobilization, income generation and grassroots-level institution building (Kanel 2004). In addition to a range of factors that contributed to shaping community- friendly policies on CF, the compliance of CFUG, local knowledge, skills and forest management systems, and adaptive capacity of local leaders also play a significant role in bringing those changes at grassroots level. These changes can be further enhanced and institutionalized through the empowerment and capacity building of communities and their leaders. The REDD+ scheme can build on these initiatives so as to bring further institutional innovations for strengthening its outcomes.

If CFUG members are directly involved in the formulation of rules and regulations, and are aware of updates to these rules, they become motivated in compliance of those rules. However, the provisions made in the CFUGs' constitutions and OPs are highly complex and impractical, especially when they are prepared under the influence of external ideas and/or agents. Since REDD+ is an external concept for CFUGs, the real forest stewards might have less motivation in respect of REDD+ activities, which may lead to less compliance of rules and less trust among stakeholders. Therefore, adequate awareness and information flow regarding the process and implications of REDD+ is important so that potential conflicts are avoided through enactment and compliance of policy and building trust among stakeholders.

The lessons learned on forest governance and management from past deliberations and reflections can be instrumental in better understanding the implications of the REDD+ scheme. In order to capitalize on this, participatory monitoring, self-reflection, interaction and review of CFUGs' practices, in addition to sustainable management of forest, may need to be strengthened and adapted as part of CFUGs' organizational culture. These organizational cultures may need to be duly recognized and respected by other stakeholders and collaborators that are engaged in REDD+ so that they can learn from the practices of CFUGs and institutionalize the same in the REDD+ process. However, looking at the 
cultural practices of Nepal's CF, more powerful and resource-rich actors might have undue dominant role in the collaboration and, therefore, institutional cross learning might be curtailed.

The existence of a few provisions related to biodiversity, payment for environmental services or carbon trade in the OPs indicates that they are aware of the broader and macro-level issues related to forest. However, FGDs indicated that these provisions were particularly made due to the influence of external agents/facilitators and CFUG members lacked knowledge of global and national forestry issues and trends in forestry policies and discourses. This is partly due to lack of opportunities in engaging with the macrolevel forestry issues. As REDD+ is also a newly emerging international initiative, there is high likelihood that most of the CFUGs lack competency in engaging in the REDD+ processes. Capacity building, partnership and collaboration, resource provisioning and safeguards might be useful for increased engagement of CFUGs in REDD+.

\section{Effectiveness and Efficiency}

Though REDD+ is considered as one of the effective strategies for reducing carbon emissions, there are a range of challenges and risks associated with formulating a policy and setting up institutional provisions at different levels. Within a country, grassroots-level institutional provisions and practices might have greater bearing in determining the outcomes of REDD+.

In situations where local people largely depend on forest resources, devolution of forest management rights has been an effective strategy as it has addressed both the livelihood and forest management needs of local communities. However, there are tradeoffs in the outcomes of forest management that are acceptable to the communities and the state. Though the transfer of resource ownership to communities is identified as a feasible and cost-effective strategy for poverty reduction (Arnold 2001), application of this idea in the REDD+ context may be contested. In the context of REDD+, the main and prioritized objective of forest management is to reduce the emissions from the forest and, therefore, its tradeoff with poverty and livelihood outcomes may not be considered as REDD+ outcomes for payment. In the situation where co-benefits are not considered for payment, the enthusiasm of forestdependent communities towards managing forest may be less. So far, there is no clarity on the very objectives, targets and co-benefits of REDD + that may be rewarded through payment and, therefore, its effectiveness seems to be unclear.

A focus on participatory approaches to forest management and defining clear land tenure and carbon rights may lead to effective and efficient outcomes of REDD+. Moreover, CFUGs' governance, backed by legislation, has increased the effectiveness and efficiency of CF (Kanel 2004), which may contribute towards success of REDD+ in Nepal. However, it is advisable to strengthen the REDD+ programme by formulating explicit national legislation for the REDD+ scheme to operate so as to ensure effectiveness and efficiency in the outcomes.

\section{CONCLUSION}

Better governance of forest management communities has been considered as one of the prerequisites of REDD+ to be effective in its outcome. Efforts are inadequate in synthesizing past forest governance lessons and linking them with the REDD+ policy development process. This study shows that the lessons gained through the study of CFUGs' governance could be instrumental in designing REDD+ governance at grassroots level and realize its outcomes effectively. As a local-level institution managing forest successfully for more than three 
decades, CFUGs might take viable and effective grassroots initiatives for implementing REDD+ so as to reduce emissions as well as securing cobenefits at optimum level. Also, while assessing through key parameters of governance, CFUGs are found to be appropriate institutions at grassroots level for REDD+ interventions. However, capacity building, empowerment and additional resources might be needed for them to carry out additional activities related to REDD+. It is also important to make CFUGs inclusive so as to create a feeling of ownership by all local people. Failure to do so may weaken governance, resulting in weak negotiation capacity of CFUGs, at both policy and practice levels.

Some of the specific key findings and observations of the study that might be related to REDD+ are as follows:

- Under the current CF policy framework, CFUGs' access to forest resources, particularly for fulfilling the subsistence needs of forest products, has been secured through a range of locally devised policies and mechanisms. Therefore, the existing CF policy by and large may be useful in providing a space for CFUGs to exercise their rights over use of forest products at local level. However, gaining benefits from the environmental services, including carbon sequestration and REDD+ scheme, may need a more explicit and elaborate policy framework.

- A range of effective and locally suitable governance measures that promote participation, accountability and transparency are devised and applied at CFUG level. Such measures themselves (or at least the lessons gained through them in $\mathrm{CF}$ ) might be equally relevant to improve REDD+ grassroots level governance in both technical and financial aspects.
- Participatory planning and a bottom-up decision-making process have been institutionalized in the CFUGs and therefore, the ownership of the CFUG members has increased in CFUG activities. However, these processes have often been handicapped by formalities and elite captures. Therefore, care should be taken while the lessons from CF are taken over to REDD+.

- So far, dynamics of power relations between CF stakeholders have greater bearing in the functioning of CFUGs, particularly in selecting leaders and sharing benefits. It is perhaps due to the engagement of people in the current process of political transformation. Existing power relations could be changed through REDD+ implementation since the private sector might enter the stakeholder landscape and might have greater say due to their role in financial transactions.

- Despite having clear vision, strong commitment, passion and action for forest management on the part of CFUGs, the individuals or institutions supporting CFUGs either from within it or from the external environment may have great influence in the CFUGs' change process. Therefore, the role of facilitating individuals and institutions is important not only to convey the message on REDD+ in the CFUGs but also to institutionalize it.

- Though the CFUG members' compliance of approved constitution and OP indicates encouraging sign for the success of CF, little organized and institutionalized selfmonitoring and reflection of the broader context and past deeds might cause constraints on REDD+ implementation. Perhaps special consideration and investment in this aspect of community 
action might add value to synergize REDD+ outcomes.

- The collaboration and partnership that the CFUGs have made so far with different local institutions might provide an opportunity for learning that can be used to forge broader collaboration for REDD+ as well as community development.

- Consideration of macro environment and their chain effect at grassroots level is important to provide policy feedback for ensuring forest rights of local communities. However, it is still questionable whether CFUGs can secure community rights over forest resources and equitable share of benefits even if they respond to the macrolevel policy environment where mechanisms such as REDD+ are evolving.

\section{REFERENCES}

Agarwal, B. 2001. Participatory Exclusions, Community Forestry, and Gender: An Analysis for South Asia and a Conceptual Framework. World Development, 29(1): 16231648 .

Agrawal, A. and Angelsen, A. 2009. Using Community Forest Management to Achieve REDD+ Goals. In: A. Angelsen, with M. Brockhaus, M. Kanninen, E. Sills, W.D. Sunderlin, and S. Wertz-Kanounnikoff (Eds.), Realising REDD+: National strategy and policy options (pp. 201-212). CIFOR, Bogor, Indonesia.

Angelsen, A. and McNeill, D. 2012. The Evolution of REDD+. In: A. Angelsen, M. Brockhaus, W.D. Sunderlin, and L.V. Verchot (Eds.), Analysing REDD+: Challenges and Choices. CIFOR, Bogor, Indonesia.

Arnold, J.E.M. 2001. Forests and People: 25 Years of Community Forestry. Rome: Food and Agriculture Organization.

Arnold, J.E.M. and Stewart, W.C. 1991. Common Property Resource Management in India. Oxford: Oxford Forestry Institute, University of Oxford.

CFD. 2009. Community Forestry Guideline. Kathmandu: Community Forestry Division, Ministry of Forests and Soil Conservation

Charnley, S. and Poe, M. 2007. Community Forestry in Theory and Practice: Where are We Now? Annual Review of Anthropology, 32:301-336.

Kanel, K.R. 2004. Twenty-five Years' Community Forestry: Contribution to Millennium Development Goals. Twenty- five Years of Community Forestry, Proceedings of the Fourth National Workshop on Community Forestry (pp. 4-18). Kathmandu: Community Forest Division, Department of Forests.

Khatri, D. 2012. Is REDD+ Redefining Forest Governance in Nepal? Journal of Forest and Livelihoods, 10(1): 74-87.

Luintel, H., Bhattarai, B. and Ojha, H.R. 2007. Internal Group Governance in the Context of Community Based Forest Management: A Review of Recent Innovations and an Analytical Framework. RECOFTC, Bangkok, Thailand.

Luintel, H., Ojha, H., Rana, B., Subedi, R. and Dhungana, H. 2009. Community Forestry in Nepal: Promoting Livelihoods, Community Development and the Environment. ForestAction Nepal and Livelihoods and Forestry Programme.

Pokharel, B.K. 2006. Contribution of Community Forestry to People's Livelihoods and Forest Sustainability: Experience from Nepal. World Rainforest Movement, Montevideo, Uruguay (http://www.wrm.org.uy/countries/Asia/ Nepal.html accessed on 5 October 2010)

Pokharel, B.K. and Niraula, D.R. 2004. Community Forestry Governance in Nepal: Achievements, Challenges and Options for the Future. Twenty Five Years of Community Forestry, Proceedings of the Fourth National Workshop on Community Forestry (pp. 298-316). Kathmandu: Community Forest Division, Department of Forests.

Pokharel, B.K. and Nurse, M. 2004. Forests and People's Livelihoods: Benefiting the Poor from Community Forestry. Journal of Forests and Livelihoods, 4(1): 19-29.

Pokharel, B.K., Branney, P., Nurse, M. and Malla, Y.B. 2007. Conserving Forests, Sustaining Livelihoods and Strengthening Democracy. Journal of Forest and Livelihoods, 6(2).

Poudyal, B.H. Paudel, G. and Luintel, H.S. 2010. Case Study on Internal Group Governance in the Community Forest User Groups of Nepal. Bangkok, Thailand: RECOFTC.

Ribot, J.C., Chhatre, A., Lankina, T. 2008. Institutional Choice and Recognition in the Formation and Consolidation of Local Democracy. Conservation and Society, 6(1): 1-11.

Robledo, C., Blaser, J., Byrne, S. and Schmidt, K. 2008 Climate Change and Governance in the Forest Sector. An Overview of the Issues on Forests and Climate Change with Specific Consideration of Sector Governance, Tenure and Access for Local Stakeholders. Washington, D.C.: Rights and Resources Institute.

Sikor, T., Stahl, J., Enters, T., Ribot, J.C., Singh, N. Sunderlin, W.D. and Wollenberg, L. 2010. REDD-plus, Forest People's Rights and Nested Climate Governance. Global Environmental Change, 20(3). 
Springate- Baginski, O., Yadav, N.P., Dev, O.P. and Soussan, J. 2003. Institutional Development of Forest User Groups in Nepal: Processes and Indicators. Journal of Forest and Livelihood,3(1).

Springate-Baginski, O. and Wollenberg, E. (Eds.). 2010 REDD, Forest Governance and Rural Livelihoods: the Emerging Agenda. CIFOR, Bogor, Indonesia.

Stern, N. 2006. The Stern Review: the Economics of Climate Change. Cambridge University Press.
Venter, O., Laurance, W.F., Iwamura, T., Wilson, K.A. Fuller, R.A. and Possingham, H.P. 2009. Harnessing Carbon Payments to Protect Biodiversity. Science, 326: 1368.

Visseren-Hamakers, I.J., McDermott, C., Vijge, M.J. and Cashore, B. 2012. Trade-offs, Co-benefits and Safeguards: Current Debates on the Breadth of REDD+. Current Opinion in Environmental Sustainability, 4: 646-653. 